\title{
Effect of ozone exposure on Amyotrophic Lateral Sclerosis (ALS) pathology using a mice model of TDP-43 proteinopathy
}

Ana Rodriguez $^{\mathrm{a}}$, Agueda Ferrer-Donato ${ }^{\mathrm{b}}$, Marta Cabrera-Pinto ${ }^{\mathrm{b}}$, Susana Seseña ${ }^{\mathrm{a}}$, Paloma Fernández c, Alfonso Aranda ${ }^{\mathrm{d}}$ and Carmen M. Fernandez-Martos ${ }^{\mathrm{b}, \mathrm{e}}$.

${ }^{\text {a }}$ Faculty of Environmental Sciences and Biochemistry, University of Castilla-La Mancha (UCLM), Toledo, Spain.

${ }^{\mathrm{b}}$ Research Unit of the National Hospital of Paraplegics (UDI-HNP), Toledo, Spain.

${ }^{c}$ Institute of Applied Molecular Medicine (IMMA), Faculty of Medicine, Universidad San Pablo CEU, Madrid, Spain.

${ }^{\mathrm{d}}$ Faculty of Chemical Science and Technology, University of Castilla-La Mancha, (UCLM), Ciudad Real, Spain

${ }^{\mathrm{e}}$ Wicking Dementia Research and Education Centre, College of Health and Medicine, University of Tasmania, Hobart, Tasmania, Australia.

Corresponding author: Dr. Carmen M. Fernandez-Martos. Primary Email: cmfernandezm@sescam.jccm.es. Secondary Email: Carmen.fernandezmartos@utas.edu.au.Finca La Peraleda s/n, Toledo 45007, Spain.

Phone: +34 925 247789; Fax: +34 925247745 . 


\begin{abstract}
Background: Ozone $\left(\mathrm{O}_{3}\right)$, one of the main photochemical pollutants in the atmosphere today, is a serious health risk factor. Although the effects of $\mathrm{O}_{3}$ exposure have been documented on many diseases, they have not yet been examined on Amyotrophic Lateral Sclerosis (ALS)- a fatal progressive and neurodegenerative disease.
\end{abstract}

Objectives: To investigate the effect of the $\mathrm{O}_{3}$ exposure in a mice model of TDP-43 proteinopathy, exploring a possible association between the $\mathrm{O}_{3}$ exposure and the ALS pathogenesis.

Methods: TDP-43 ${ }^{\mathrm{A} 315 \mathrm{~T}}$ and wild-type (WT) mice were exposed to $\mathrm{O}_{3}(0.25 \mathrm{ppm})$ or filtered air (FA) for 15 days (4 hours/day). We assessed (1) weight loss (2) motor performance (3) plasma glucose content and (4) metabolic markers from plasma samples of the animals.

Results: Throughout the experiment, we observed a progressive decline in body weight and the motor coordination in TDP- $43^{\mathrm{A} 315 \mathrm{~T}}$ mice compared to WT controls. Although there was a trend, there were no significant differences in the decline of body weight of TDP-43 ${ }^{\mathrm{A} 315 \mathrm{~T}}$ mice when exposed to either FA or $\mathrm{O}_{3}$. In $\mathrm{O}_{3}-\mathrm{TDP}-43^{\mathrm{A} 315 \mathrm{~T}}$ mice, the disease duration lasted longer. In addition, $\mathrm{O}_{3}-\mathrm{TDP}-43^{\mathrm{A} 315 \mathrm{~T}}$ mice showed improvements in motor performance as well TDP-43 ${ }^{\mathrm{A} 315 \mathrm{~T}}$ mice were hypoglycemic compared to WT mice. However, FA-TDP-43 ${ }^{\mathrm{A} 315 \mathrm{~T}}$ mice showed lower plasma glucose levels at the disease end-stage. We found altered levels of adipokines and metabolic proteins in TDP-43 ${ }^{\mathrm{A} 315 \mathrm{~T}}$ mice compared to WT controls. A positive correlation was found among GIP and glucagon compared to insulin concentrations in control mice. Interestingly, resistin, Gastric Inhibitory Peptide (GIP), Glucagon Like Peptide 1 (GIP-1) and insulin levels were higher in $\mathrm{O}_{3}$-TDP-43 ${ }^{\mathrm{A} 315 \mathrm{~T}}$ mice.

Discussion: We provide new evidence about a mechanistic link between $\mathrm{O}_{3}$ exposure and the improvement of the metabolic disturbances present in TDP-43 ${ }^{\mathrm{A} 315 \mathrm{~T}}$ mice. Further studies are needed to corroborate the obtained results as they warrant to understanding the underlying mechanisms. 


\section{Introduction}

Environmental pollution is considered an international public health issue with multiple facets (Manisalidis et al. 2020). As urbanization and industrialization have reached unprecedented proportions worldwide in our era, ambient air pollution has become one of the biggest public health hazards worldwide, accounting for about 4 million deaths per year (Hoffmann et al. 2020; Sacks et al. 2020). Among the most pertinent air pollutants, tropospheric ozone $\left(\mathrm{O}_{3}\right)$ stands out for its harmful health and environmental effects, contributing to climate change as a greenhouse effect gas. $\mathrm{O}_{3}$ is a highly oxidative gas that is formed by the action of solar radiation from photochemical reactions of other pollutants (i.e. nitrogen oxides, and volatile organic compounds) emitted by vehicles and manufacturing (Humans 2016). The toxic effects induced by $\mathrm{O}_{3}$ are registered in urban areas all over the world, causing biochemical, morphologic, functional, and immunological disorders (Lippmann 1989). Epidemiological studies have also shown associations between $\mathrm{O}_{3}$ exposure and increased morbidity and mortality (Vicedo-Cabrera et al. 2020). In fact, at present, $\mathrm{O}_{3}$ is already causing 55.000 premature deaths due to long-term exposure annually in Europe (Orru 2019). Furthermore, if we take into account the fact that $\mathrm{O}_{3}$ formation is temperature-dependent, and considering the impact of the changing climate, we can expect up to an $11 \%$ increase in ozone-associated mortality in some countries in Central and Southern Europe in 2050 (Orru 2019).

Extensive investigation about $\mathrm{O}_{3}$-related pathophysiological sequelae clearly show that exposure to this pollutant causes and exacerbates respiratory (D'Amato et al. 2019; Manisalidis et al. 2020; Sokolowska et al. 2019) and cardiovascular diseases (Bourdrel et al. 2017; Manisalidis et al. 2020; Song et al. 2020). What is more, $\mathrm{O}_{3}$ exposure could also increase the incidence of chronic metabolic disorders, obesity and diabetes type II (Shore 2019; Thomson et al. 2018), which has become one of the greatest global health threats of the 21 st century. Furthermore, in humans, this pollutant increases the release of stress hormones, cortisol or rodent corticosterone (Thomson et al. 2018), and alters the metabolic and endocrine response to the glucose challenge, which could also contribute to metabolic dysregulation (Thomson et al. 2018). Remarkably, a growing number of studies strongly suggests 
that certain neurological pathologies, such as Alzheimer's disease (Bello-Medina et al. 2019a; RivasArancibia et al. 2010) and Parkinson's disease (Kremens et al. 2014; Ritz et al. 2016), might be associated with the $\mathrm{O}_{3}$ exposure through a variety of molecular and cellular pathways that either damage brain tissue directly, or lead to a predisposition to these neurological alterations (Genc et al. 2012). Epidemiological evidence supporting this association is still limited, and the underlying mechanisms are poorly understood. As suggested by different studies (Filippini et al. 2020; Povedano et al. 2018; Yu et al. 2014), some environmental and occupational risk factors, including air pollution, could be associated with the occurrence of Amyotrophic Lateral Sclerosis (ALS). However, even though evidence exists of a potential link between air pollution and ALS, to date, no study has investigated this association.

ALS is a motor neuron disease characterized by the selective and progressive loss of upper and lower motor neurons of the cerebral cortex, brainstem, and spinal cord (Tapia 2014). The result of this loss is a rapidly progressive paralysis, which ultimately leads to death within three to five years of symptom onset. The estimated prevalence of this fatal disease is 5 per 100,000 in the United States and approximately 2-3 people per 100,000 of the general population in Europe. ALS, therefore, represents one of the most challenging socio-economic problems of our future. The majority of patients suffer from sporadic ALS (sALS; more than 90\%), in which multiple risk factors from geneenvironment interactions contribute to the disease pathogenesis. In contrast, only a small subset of patients suffers from familial ALS (fALS; less than 10\%) due to their associated genetic dominant inheritance factor (Zarei et al. 2015). No gene-conferring susceptibility to a certain environmental exposure has been established in ALS. Indeed, the recognized mechanisms by which mutations or gene-environment interactions cause the progressive degeneration and death of motor neurons have not been elicited yet. To date, only two epidemiology studies have investigated the possible association between $\mathrm{O}_{3}$ exposure and the risk of ALS (Myung et al. 2019; Povedano et al. 2018). Only smoking has been firmly established to increase the risk for ALS (Oskarsson et al. 2015). 
It has already been demonstrated that $\mathrm{O}_{3}$ exposure increases the risk of acute respiratory distress syndrome (Rhee et al. 2019), and recently it has been found that it could induce chronic state oxidative stress (Bello-Medina et al. 2019b). Progressive neuromuscular respiratory failure is the most common cause of mortality in ALS patients (Chio et al. 2009), and, while it is unclear whether oxidative stress is a primary or a secondary cause of neurodegeneration in ALS, data from both human tissue and studies in animal models of ALS suggest that oxidative stress is a major contributory factor leading to chronic motor neuron death (Barber et al. 2006; Petri et al. 2012). Therefore, there is a great need for studies to identify $\mathrm{O}_{3}$ as a risk factor to this disease since a better understanding of environmental risk factors could help to reduce exposures and it is hoped to markedly reduce ALS incidence over time.

In this context, our research evaluates in vivo the effect of the $\mathrm{O}_{3}$ exposure in the well-validated TDP$43^{\mathrm{A} 315 \mathrm{~T}}$ murine model of TDP-43 proteinopathy, which recapitulates several aspects of the human ALS, providing, to our knowledge, the first insights into the association between the exposure to the $\mathrm{O}_{3}$ and the pathogenesis of ALS. Our studies highlight the importance of tailoring the use of animal models to the experimental question being addressed, to ensure translatability of findings. 


\section{Methods}

\section{Animals}

Both mutant TAR DNA-binding protein 43 (TDP43 ${ }^{\mathrm{A} 315 \mathrm{~T}}$ ) mice (Wegorzewska et al. 2009) and age and gender-matched non-transgenic littermates (WT controls) (Strain No. 010700, Bar Harbor, ME, USA) were used in this study. This mouse model of ALS was generated using the mouse prion promoter (Prt) and a cDNA encoding human TARDBP with an A315T mutation (hTDP-43 ${ }^{\mathrm{A} 315 \mathrm{~T}}$ ) associated with fALS and containing an N-terminal FLAG-tag (Wegorzewska et al. 2009). These mice accumulate cytoplasmic TDP-43 in the brain and spinal cord, including TDP-43 aggregates (Ke et al. 2015). They do not, however, develop neuronal loss or paralysis (Wegorzewska et al. 2009). For all the experiments, TDP-43 ${ }^{\mathrm{A} 315 \mathrm{~T}}$ mice were used as hemizygotes. The $\mathrm{Tg}$ progeny were genotyped at 21 days of age by detecting hTDP-43 transgene using standard tail genomic DNA PCR analysis according to the distributor's protocol. To avoid the ambiguity associated with reported gender-related differences in mean survival time of TDP-43 ${ }^{\mathrm{A} 315 \mathrm{~T}}$ mice (Hatzipetros et al. 2014; Wegorzewska et al. 2009), we used only male mice. The animals were group-housed under standard housing conditions with a $12 \mathrm{~h}$ light-dark cycle, and food and water ad libitum. TDP-43 ${ }^{\mathrm{A} 315 \mathrm{~T}}$ mice were fed jellified food in pellet form (D5K52 food. Rettenmaier Ibérica, Spain) to mitigate the intestinal dysmotility phenotype and sudden death (Herdewyn et al. 2014), and their general health was regularly checked. All experimental procedures were approved by the Animal Ethics Committee of the National Hospital for Paraplegics (HNP) (Approval No 26/OH 2018), in accordance with the Spanish Guidelines for the Care and Use of Animals for Scientific Purposes.

\section{$\mathrm{O}_{3}$ exposure}

Forty-two-day-old TDP-43 ${ }^{\mathrm{A} 315 \mathrm{~T}}$ mice and WT controls were divided in two groups, and exposed to $\mathrm{O}_{3}$ (9/ group, $\mathrm{n}=3$ TDP-43 ${ }^{\mathrm{A} 315 \mathrm{~T}}$ mice vs. $\mathrm{n}=6 \mathrm{WT}$ mice) or filtered air (FA) (9/ group, $\mathrm{n}=3$ TDP$43^{\mathrm{A} 315 \mathrm{~T}}$ mice vs. $\mathrm{n}=6 \mathrm{WT}$ mice). In all cases, animals were exposed 15 consecutive days (4 hours/ day) following the protocol described by Bello-Medina et al. (Bello-Medina et al. 2019a). $\mathrm{O}_{3}$ was generated from pure $\mathrm{O}_{2}$ with a BTM $802 \mathrm{~N}$ generator and distributed in a Plexiglas chamber $(50 \times 35$ 
$\mathrm{x} 35 \mathrm{~cm}$ ) together with zero air at a total flow of $15 \mathrm{~L} / \mathrm{min} . \mathrm{O}_{3}$ concentration of the ambient air in the chamber was kept constant at $0.25 \mathrm{ppm}$ and was continuously monitored by an Environment $\mathrm{O} 342 \mathrm{M}$ analyzer (Envea, France). FA was obtained by filtering regular air with activated charcoal to reduce $\mathrm{O}_{3}$ concentration to a minimum of $(<0.02 \mathrm{ppm})$. During the exposures, animals had free access to food and water, and their general health was regularly checked.

\section{Monitoring and behavioral assessments}

To monitor disease progression and onset-stage (defined as the last day of individual peak body weight before gradual loss occurs) determination, body weight lost was measured and motor performance was evaluated using rotarod test. All mice were weighed and assessed three times per week until the disease onset-stage. After that mice were then checked daily in the morning until the disease end-stage (defined as the weight below $80 \%$ of the initial weight on each of three consecutive days).

The rotarod motor test was performed on all mice once a week (Dang et al. 2014), starting from the 6 weeks of age until the day of euthanasia. Animals were previously trained for three consecutive days and three times a day to promote the learning of the task. The accelerated protocol was applied for this motor monitoring as described previously by Mandillo et al. (Mandillo et al. 2008). In brief, mice were placed on a rotarod apparatus (Model 7650, Ugo Basile) at a speed of $4 \mathrm{rpm}$ with acceleration up to $40 \mathrm{rpm}$ over $300 \mathrm{~s}$. Three tests were performed for each mouse with a minimal interval of 20 mins, and the average of the longest two performances was taken as the final result for analysis.

\section{Measurement of plasma glucose content}

At disease end-stage ( 95-100 \pm 2 days), animals were terminally anesthetized with sodium pentobarbitone $(140 \mathrm{mg} / \mathrm{kg})$ and the whole blood was collected by cardiac puncture (Bewick et al. 2009). Immediately, glucose levels were measured using a glucometer (FreeStyle Optium ${ }^{\mathrm{TM}} \mathrm{Neo} \mathrm{H}$ glucometer, Abbott Diabetes Care Inc, USA), previously calibrated for plasma glucose levels. The samples remaining after the glucometer measurements were immediately centrifuged at $3380 \mathrm{~g}$ for 
$10 \mathrm{~min}$ at room temperature to separate plasma samples (Togashi et al. 2016), which were immediately frozen on dry ice and stored at $-80{ }^{\circ} \mathrm{C}$ for later analysis.

\section{Measurement of metabolic markers plasma}

Adipokines (ghrelin, resistin and leptin) and metabolic biomarkers of insulin resistance from plasma samples were both analyzed by duplicate using the Bio-PlexPro mouse Diabetes group from Bio-Rad (Ref. 171F7001M), in a Luminex ${ }^{\circledR} 200^{\mathrm{TM}}$ technology as previously described (Ortega Moreno et al. 2020). Samples were processed following the manufacturer's instructions. The final concentration value of each metabolic marker was the result of the mean from the two duplicated measures.

\section{Statistical analysis}

All data are presented as means \pm standard error of the mean (SEM). Differences between means were assessed by two-way ANOVA followed by Tukey post hoc analysis. When only two groups were analyzed, a two-tailed Student $t$-test was used (equal variances assumed). For multiplex assays, the median for each sample group was determined for all the analytes, and Kruskal-Wallis test was performed. Spearman correlation was performed for both the adipokines and metabolic proteins, respectively. For all statistical tests, a $p$ value of $<0.05$ (CI 95\%) was assumed to be significant. Statistical analysis was performed using GraphPad Prism software (version 8.3.1).

\section{Results}




\section{Evaluation of $\mathrm{O}_{3}$ exposure on disease progression}

To evaluate the effect of $\mathrm{O}_{3}$ exposure on disease progression, we monitored body weight loss and motor performance until the disease end-stage in WT controls and TDP-43 ${ }^{\mathrm{A} 315 \mathrm{~T}}$ mice exposed to $\mathrm{O}_{3}$ or FA for 15 days beginning at 42 days of age (on week 6). As TDP-43 ${ }^{\mathrm{A} 315 \mathrm{~T}}$ mice exhibit weight loss during disease progression (Esmaeili et al. 2013; Guo et al. 2012; Hatzipetros et al. 2014; Medina et al. 2014), we assessed the capacity of $\mathrm{O}_{3}$ exposure to modify weight changes over time. For this reason, the mice were weighed three times per week until the disease onset-stage. Then, the mice were weighed daily, and an average of the weights for each week was evaluated. Starting on week 8. During the 15 days of exposure, no differences in weight gain between groups $\left(\mathrm{O}_{3}\right.$ group vs. FA group) were displayed (Figure 1). A two-way ANOVA with repeated measures revealed a significant genotype interaction (Figure $2 \mathrm{~A} ; F_{(15,81)}=87.72, p<0.0001$ ), indicating a sustained decline in body weight in TDP-43 ${ }^{\mathrm{A} 315 \mathrm{~T}}$ mice compared to WT controls in responses to FA or $\mathrm{O}_{3}$ over time. However, although there was a trend, no significant differences were observed between FA-exposed or $\mathrm{O}_{3}$ exposed TDP-43 ${ }^{\mathrm{A} 315 \mathrm{~T}}$ mice, indicating that $\mathrm{O}_{3}$ exposure had no significant effect on weight loss in TDP-43 ${ }^{\mathrm{A} 315 \mathrm{~T}}$ mice. In addition, the calculation of the disease onset using this parameter indicated that TDP-43 ${ }^{\mathrm{A} 315 \mathrm{~T}} \mathrm{O}_{3}$-exposed develop symptoms later than FA-treated TDP-43 ${ }^{\mathrm{A} 315 \mathrm{~T}}$ mice. Using body weight measurements (criterion of $10 \%$ body weight loss) an average onset of $75 \pm 5$ days of age was determined for in TDP-43 ${ }^{\mathrm{A} 315 \mathrm{~T}}$ mice in responses to FA, whereas in responses to $\mathrm{O}_{3}, \mathrm{TDP}-43^{\mathrm{A} 315 \mathrm{~T}}$ mice presented a phenotype at $83 \pm 1$ days of age (Figure $2 \mathrm{~B}$ ). To further assess changes in weight due to the effect of $\mathrm{O}_{3}$ exposure on disease progression based on the determined disease onset, we calculated disease duration (Figure 2C). Average disease duration of the animal was calculated as the time between the onset of disease and the day of death. Interestingly, while there were no significant differences in the decline of body weight in TDP-43 ${ }^{\mathrm{A} 315 \mathrm{~T}}$ mice in responses to FA or $\mathrm{O}_{3}$ over time, comparatively the disease duration was longer in TDP- $43^{\mathrm{A} 315 \mathrm{~T}}$ mice in responses to $\mathrm{O}_{3}$ (Figure $2 \mathrm{C}$ ), although $\mathrm{O}_{3}-\mathrm{TDP}-43^{\mathrm{A} 315 \mathrm{~T}}$ mice did not live significantly longer compared with FA-TDP-43 ${ }^{\mathrm{A} 315 \mathrm{~T}}$ mice. 
Furthermore, we also tested motor behavior to determine if $\mathrm{O}_{3}$ exposure beginning during the asymptomatic stage of the disease could alter disease phenotype. We analyzed the time spent on an accelerating rotarod starting from the age of 6 weeks. Lower scores on the rotarod are indicative of impaired locomotor function. Our results indicate a progressive decline in motor coordination in TDP-43 ${ }^{\mathrm{A} 315 \mathrm{~T}}$ mice, confirming the progressive motor deficits of the TDP-43 ${ }^{\mathrm{A} 315 \mathrm{~T}}$ mouse model reported previously (Stallings et al. 2010). A two-way ANOVA with repeated measures revealed a significant interaction of the group by week (Figure $2 \mathrm{D} ; F_{(6,97)}=3.051 p<0.008$ ), indicating differential change over time in rotarod performance. However, $\mathrm{O}_{3}$-exposed TDP-43 ${ }^{\mathrm{A} 315 \mathrm{~T}}$ mice showed a significant improvement in motor performance at later time points, indicating the effect of $\mathrm{O}_{3}$ exposure on motor function. Indeed, the rotarod test displayed that FA-exposed TDP-43 ${ }^{\mathrm{A} 315 \mathrm{~T}}$ mice suffer a more significant drop in performance and progressive impairment in motor capacity over time.

Overall, although $\mathrm{O}_{3}$ exposure had no significant effect on disease-associated weight loss in TDP$43^{\mathrm{A} 315 \mathrm{~T}}$ mice, our results indicate that TDP-43 ${ }^{\mathrm{A} 315 \mathrm{~T}}$ mice exposed to $\mathrm{O}_{3}$ developed a significant motor and coordination improvement.

\section{Evaluation of $\mathrm{O}_{3}$ exposure in plasma glucose levels}

We next aimed to determine if plasma glucose levels, were altered in TDP-43 ${ }^{\mathrm{A} 315 \mathrm{~T}}$ mice exposed to $\mathrm{O}_{3}$ or FA as imbalanced energy homeostasis is a consistent finding in different ALS mice (Kim et al. 2011). $\mathrm{O}_{3}$ exposure had a significant effect on plasma glucose levels of WT controls $(221.5 \pm 8.596$ $\mathrm{mg} / \mathrm{dL}$ vs. $167.2 \mathrm{mg} / \mathrm{dL} \pm 14.26 ; p<0.004$ ) (Figure 3 ). In addition, our results indicated that with either FA or $\mathrm{O}_{3}$-exposed, TDP-43 ${ }^{\mathrm{A} 315 \mathrm{~T}}$ mice were hypoglycemic compared to WT mice at the disease end-stage (Figure 3), confirming the disturbances in the energy metabolism of the TDP-43 ${ }^{\mathrm{A} 315 \mathrm{~T}}$ mouse model reported previously (Chiang et al. 2010). Interestingly, FA-TDP-43 ${ }^{\mathrm{A} 315 \mathrm{~T}}$ mice showed lower plasma glucose levels at later time points (96 mg/ dL \pm 13.39 vs. $142.3 \mathrm{mg} / \mathrm{dL} \pm 30.14, p<0.18$ ) (Figure 3), indicating that TDP-43 ${ }^{\mathrm{A} 315 \mathrm{~T}}$ mice exposed to $\mathrm{O}_{3}$ required less energy demand in the late symptomatic stage. 


\section{Evaluation of $\mathrm{O}_{3}$ exposure in adipokines and metabolic proteins}

To evaluate the effect of $\mathrm{O}_{3}$ exposure on the adipose tissue, serves as the body's major energy storage compartment, and secretes numerous endocrine mediators, we measured the levels of adipokines that influence metabolism. The expression of ghrelin, resistin and leptin in TDP-43 ${ }^{\mathrm{A} 315 \mathrm{~T}}$ mice and WT controls is presented in Table 1. We found altered levels of these adipokines in the plasma of TDP$43^{\mathrm{A} 315 \mathrm{~T}}$ mice compared to WT controls. The concentration of resistin in plasma was significantly higher in $\mathrm{O}_{3}$-exposed TDP-43 ${ }^{\mathrm{A} 315 \mathrm{~T}}$ mice, however, there was no difference in levels of ghrelin and leptin between TDP-43 ${ }^{\mathrm{A} 315 \mathrm{~T}}$ mice exposed to either $\mathrm{O}_{3}$ or FA (Table 1). In addition, $\mathrm{O}_{3}$ exposure had a significant effect on the plasma concentration of leptin in WT mice. However, no correlation was found among the serum adipokines levels in WT controls or TDP-43 ${ }^{\mathrm{A} 315 \mathrm{~T}}$ mice exposed to $\mathrm{FA}$ or $\mathrm{O}_{3}$, respectively (Figure 4A, B). Moreover, for metabolic proteins, we observed altered levels of GIP, GLP-1, glucagon, and insulin in the plasma of TDP-43 ${ }^{\mathrm{A} 315 \mathrm{~T}}$ mice relative to WT controls (Table 2). Comparatively, plasma levels of GIP, GLP-1, and insulin are higher in $\mathrm{O}_{3}$-exposed TDP-43 ${ }^{\mathrm{A} 315 \mathrm{~T}}$ mice relative to FA-exposed TDP-43 ${ }^{\mathrm{A} 315 \mathrm{~T}}$ mice (Table 2), though no statistical differences were determined. It is worth noting that a positive correlation was found among the plasmatic levels of GIP and glucagon compared to insulin concentrations in WT controls (Figure 5A, B). 


\section{Discussion}

Despite recent, significant progress in the ALS research field, no cure has yet been discovered to stop the neurodegenerative progression of this disease or to improve the lives of ALS patients. The underlying pathogenesis is not fully understood, and therefore, the disease can be very difficult to identify in its earlier stages resulting in poor and late diagnosis. It is believed that an interaction between genetic and non-genetic factors, including air pollutants such as $\mathrm{O}_{3}$, may be involved in the development of ALS. However, epidemiological evidence supporting this association is very limited and poorly defined, and whether $\mathrm{O}_{3}$ exposure can modify underlying disease-related pathological changes is unclear. In this study, we sought to investigate the effects of $\mathrm{O}_{3}$ exposure in TDP-43 ${ }^{\mathrm{A} 315 \mathrm{~T}}$ mice, which develop neuropathology and behavioral deficits similar to human ALS. Unexpectedly, our results displayed that $\mathrm{O}_{3}$ exposure did not alter disease onset, progression, or survival of TDP$43^{\mathrm{A} 315 \mathrm{~T}}$ mice. In fact, we found that $\mathrm{O}_{3}$ exposure significantly improves motor and coordination performance of TDP- $43^{\mathrm{A} 315 \mathrm{~T}}$ mice and resulted in beneficial changes to plasma glucose levels at disease end-stage. Surprisingly despite previous studies suggesting the association between exposure to air pollutants and increased susceptibility to ALS (Filippini et al. 2020; Povedano et al. 2018; Yu et al. 2014), overall, our study supported the potential benefit of $\mathrm{O}_{3}$ in modifying ALS-like pathology and disease phenotypes in mice.

Nevertheless, extensive investigations about $\mathrm{O}_{3}$-related pathophysiological sequelae clearly show that exposure to this pollutant exacerbates respiratory diseases, such as asthma, respiratory infections, and chronic obstructive pulmonary disease (D'Amato et al. 2019; Manisalidis et al. 2020; Sokolowska et al. 2019). The adverse effect of $\mathrm{O}_{3}$ on cardiovascular diseases has been also well established (Bourdrel et al. 2017; Manisalidis et al. 2020; Song et al. 2020). However, the impact of this pollutant on metabolic alterations is less understood, even when the metabolic-impairment effects of $\mathrm{O}_{3}$ have been determined in humans (Shore 2019). In this context, our results demonstrated that $\mathrm{O}_{3}$ exposure had a significant effect on the regulation of the expression of certain adipokines and metabolic proteins that are linked to metabolic disease (i.e. obesity and diabetes type II) in WT control mice. This is 
concordant with previous mouse studies that saw that acute $\mathrm{O}_{3}$ exposure causes endocrine and metabolic changes, increasing food intake and body fat mass (Nappi et al. 2016). Interestingly, we have also identified specific alterations in levels of metabolic proteins such as GIP, PAI-1, and insulin in response to $\mathrm{O}_{3}$ exposure in TDP-43 ${ }^{\mathrm{A} 315 \mathrm{~T}}$ mice. This is also important to consider in the case of $\mathrm{O}_{3}$ exposure since it has been shown that PAI-1 and insulin are metabolic proteins associated with an increase in adiposity and body mass index (BMI) (Kahn et al. 2006; Ngo et al. 2015). Remarkably, GIP stimulates insulin secretion in response to food intake (Elliott et al. 1993). These findings suggest that $\mathrm{O}_{3}$ exposure might cause endocrine and metabolic changes in TDP-43 ${ }^{\mathrm{A} 315 \mathrm{~T}}$ mice, though the mechanism is currently unknown, which would help reduce disturbances in energy metabolism associated with the progression of ALS. Accordingly, our study indicated that $\mathrm{O}_{3}$ exposure mitigates the sustained decline in body weight in TDP- $43^{\mathrm{A} 315 \mathrm{~T}}$ mice over time. Certainly, this result is very interesting considering patients with ALS are unable to maintain their body weight, in part because of the decline in their nutritional conditions (Bouteloup et al. 2009; Desport et al. 2001). Indeed, rapid weight loss in patients with ALS disease is associated with worse disease outcomes (Ahmed et al. 2019). Likewise, disturbances in energy metabolism have been associated with the progression of human ALS (Vandoorne et al. 2018). Therefore, it would be plausible that this effect of $\mathrm{O}_{3}$ exposure on body weight gain in TDP-43 ${ }^{\mathrm{A} 315 \mathrm{~T}}$ mice could be due to increased food intake. However, there was no difference in levels of ghrelin and leptin, two appetite-stimulating hormones (Klok et al. 2007), between FA or $\mathrm{O}_{3}$-exposed, TDP-43 ${ }^{\mathrm{A} 315 \mathrm{~T}}$ mice. In contrast to these results, we find that $\mathrm{O}_{3}$ exposure had a significant effect on the plasma concentration of leptin in WT controls. Likewise, a positive correlation was found among the plasmatic levels of GIP and glucagon relative to insulin concentrations in this group, supporting previous experiments conducted in rodents, which strongly associated exposure to $\mathrm{O}_{3}$ with the development of obesity and diabetes type II (Campolim et al. 2020).

It may also be worthwhile to consider other potential disease-relevant effects of $\mathrm{O}_{3}$ exposure, for example, in the TDP-43 ${ }^{\mathrm{A} 315 \mathrm{~T}}$ mice, in which a progressive motor impairment has been described 
(Stallings et al. 2010). In our study, we observed that $\mathrm{O}_{3}$ exposure improved the progressive decline in motor coordination in TDP-43 ${ }^{\mathrm{A} 315 \mathrm{~T}}$ mice over time, and resulted in higher plasma glucose levels at later time points, raising the hope that reducing energy demand could offer benefits in ALS disease. The majority of ALS patients have glucose metabolism defects (i.e. impairments in glucose transport, glycolysis, among others) (Tefera et al. 2021), which are likely to contribute to disease. Indeed, impaired glucose homeostasis in ALS could occur, at least in part, because of higher levels of circulating glucagon (Hubbard et al. 1992). Our data indicated that TDP-43 ${ }^{\mathrm{A} 315 \mathrm{~T}}$ mice exposed to $\mathrm{O}_{3}$ developed motor and coordination improvement, correlating with a delay on the disease duration, and the premature death of characteristic of TDP-43 mice expressing hTDP-43 ${ }^{\mathrm{A} 315 \mathrm{~T}}$ transgene (Esmaeili et al. 2013; Guo et al. 2012; Hatzipetros et al. 2014; Medina et al. 2014). In addition, we found lower levels of circulating glucagon in $\mathrm{O}_{3}$-exposed TDP-43 ${ }^{\mathrm{A} 315 \mathrm{~T}}$ mice compared to FA-treated TDP-43 ${ }^{\mathrm{A} 315 \mathrm{~T}}$ mice, and a positive correlation was determined among the plasmatic levels of GIP and glucagon compared to insulin concentrations in WT controls. Remarkably, $\mathrm{O}_{3}$ exposure had a significant effect on plasma glucose levels of WT controls, suggesting that the possible causative role that $\mathrm{O}_{3}$ plays in the development of insulin resistance was not attributed to excessive energy demand alone. Therefore, since it has been suggested an increase in disease severity in ALS patients is correlated with increased circulating glucagon levels (Ngo et al. 2015), our data are congruent with the observations that insulin resistance is related to disease severity and outcome in ALS (Muddapu et al. 2020).

In summary, our findings show that $\mathrm{O}_{3}$ exposure could offer benefits to ALS patients. To date, there are only two medications, riluzole (glutamate antagonist) (Miller et al. 2002) and edaravone (free radical scavenger) (Rothstein 2017), approved by the US Food and Drug Administration (FDA) Unfortunately, none of these treatments reverse the damage already caused by ALS. Indeed, no cure is available for ALS to stop the neurodegenerative progression of ALS or to improve the lives of patients suffering from this terrible disease. Hence, it is imperative to find an effective therapy to minimize the sufferings of these patients. Our study provides the first preliminary evidence of a mechanistic link between $\mathrm{O}_{3}$ exposure and the improvement of the metabolic disturbances present in 
TDP-43 ${ }^{\mathrm{A} 315 \mathrm{~T}}$ mice. How $\mathrm{O}_{3}$ exposure contributes to disease progression of TDP-43-related disease remains unclear. Further studies are required to investigate whether $\mathrm{O}_{3}$-exposed TDP-43 ${ }^{\mathrm{A} 315 \mathrm{~T}}$ mice show alterations in levels of adipokines and metabolic proteins with an important role in regulating food intake and energy balance in the brain at late stages of the disease.

\section{Acknowledgments}


The authors would like to gratefully acknowledge the Animal Facility and Experimental Surgery Unit of the UDI-HNP for their excellent technical support. Also, we extend our gratitude to Dr Nicolas Valiente-Parra, Department of Biosciences, University of Oslo (Norway) for his assistance with the statistical analysis. This work was supported by the funding from the Consejería de Educación, Cultura y Deportes, Fondo Europeo de Desarrollo Regional (FEDER), Junta de Comunidades de Castilla-La Mancha (SBPLY/17/180501/000303).

\section{Conflict of interest}


bioRxiv preprint doi: https://doi.org/10.1101/2021.02.12.430915; this version posted February 14, 2021. The copyright holder for this preprint (which was not certified by peer review) is the author/funder. All rights reserved. No reuse allowed without permission.

The authors declare that they have no conflict of interest.

\section{References}


Ahmed RM, Phan K, Highton-Williamson E, Strikwerda-Brown C, Caga J, Ramsey E, et al. 2019. Eating peptides: Biomarkers of neurodegeneration in amyotrophic lateral sclerosis and frontotemporal dementia. Ann Clin Transl Neurol 6:486-495.

Barber SC, Mead RJ, Shaw PJ. 2006. Oxidative stress in als: A mechanism of neurodegeneration and a therapeutic target. Biochim Biophys Acta 1762:1051-1067.

Bello-Medina PC, Prado-Alcala RA, Rivas-Arancibia S. 2019a. Effect of ozone exposure on dendritic spines of ca1 pyramidal neurons of the dorsal hippocampus and on object-place recognition memory in rats. Neuroscience 402:1-10.

Bello-Medina PC, Rodriguez-Martinez E, Prado-Alcala RA, Rivas-Arancibia S. 2019b. Ozone pollution, oxidative stress, synaptic plasticity, and neurodegeneration. Neurologia.

Bewick GA, Kent A, Campbell D, Patterson M, Ghatei MA, Bloom SR, et al. 2009. Mice with hyperghrelinemia are hyperphagic and glucose intolerant and have reduced leptin sensitivity. Diabetes 58:840-846.

Bourdrel T, Bind MA, Bejot Y, Morel O, Argacha JF. 2017. Cardiovascular effects of air pollution. Arch Cardiovasc Dis 110:634-642.

Bouteloup C, Desport JC, Clavelou P, Guy N, Derumeaux-Burel H, Ferrier A, et al. 2009. Hypermetabolism in als patients: An early and persistent phenomenon. J Neurol 256:1236-1242.

Campolim CM, Weissmann L, Ferreira CKO, Zordao OP, Dornellas APS, de Castro G, et al. 2020. Short-term exposure to air pollution (pm2.5) induces hypothalamic inflammation, and long-term leads to leptin resistance and obesity via tlr4/ikbke in mice. Sci Rep 10:10160.

Chiang PM, Ling J, Jeong YH, Price DL, Aja SM, Wong PC. 2010. Deletion of tdp-43 down-regulates tbc1d1, a gene linked to obesity, and alters body fat metabolism. Proc Natl Acad Sci U S A 107:16320-16324.

Chio A, Logroscino G, Hardiman O, Swingler R, Mitchell D, Beghi E, et al. 2009. Prognostic factors in als: A critical review. Amyotroph Lateral Scler 10:310-323. 
D'Amato G, Annesi-Maesano I, Cecchi L, D'Amato M. 2019. Latest news on relationship between thunderstorms and respiratory allergy, severe asthma, and deaths for asthma. Allergy 74:9-11.

Dang TN, Lim NK, Grubman A, Li QX, Volitakis I, White AR, et al. 2014. Increased metal content in the tdp-43(a315t) transgenic mouse model of frontotemporal lobar degeneration and amyotrophic lateral sclerosis. Front Aging Neurosci 6:15.

Desport JC, Preux PM, Magy L, Boirie Y, Vallat JM, Beaufrere B, et al. 2001. Factors correlated with hypermetabolism in patients with amyotrophic lateral sclerosis. Am J Clin Nutr 74:328-334.

Elliott RM, Morgan LM, Tredger JA, Deacon S, Wright J, Marks V. 1993. Glucagon-like peptide-1 (7-36)amide and glucose-dependent insulinotropic polypeptide secretion in response to nutrient ingestion in man: Acute post-prandial and 24-h secretion patterns. J Endocrinol 138:159-166.

Esmaeili MA, Panahi M, Yadav S, Hennings L, Kiaei M. 2013. Premature death of tdp-43 (a315t) transgenic mice due to gastrointestinal complications prior to development of full neurological symptoms of amyotrophic lateral sclerosis. Int J Exp Pathol 94:56-64.

Filippini T, Tesauro M, Fiore M, Malagoli C, Consonni M, Violi F, et al. 2020. Environmental and occupational risk factors of amyotrophic lateral sclerosis: A population-based case-control study. Int J Environ Res Public Health 17.

Genc S, Zadeoglulari Z, Fuss SH, Genc K. 2012. The adverse effects of air pollution on the nervous system. J Toxicol 2012:782462.

Guo Y, Wang Q, Zhang K, An T, Shi P, Li Z, et al. 2012. Ho-1 induction in motor cortex and intestinal dysfunction in tdp-43 a315t transgenic mice. Brain Res 1460:88-95.

Hatzipetros T, Bogdanik LP, Tassinari VR, Kidd JD, Moreno AJ, Davis C, et al. 2014. C57bl/6j congenic prp-tdp43a315t mice develop progressive neurodegeneration in the myenteric plexus of the colon without exhibiting key features of als. Brain Res 1584:59-72.

Herdewyn S, Cirillo C, Van Den Bosch L, Robberecht W, Vanden Berghe P, Van Damme P. 2014. Prevention of intestinal obstruction reveals progressive neurodegeneration in mutant tdp-43 (a315t) mice. Mol Neurodegener 9:24. 
Hoffmann B, Roebbel N, Gumy S, Forastiere F, Brunekreef B, Jarosinska D, et al. 2020. Air pollution and health: Recent advances in air pollution epidemiology to inform the european green deal: A joint workshop report of ers, who, isee and hei. Eur Respir J 56.

Hubbard RW, Will AD, Peterson GW, Sanchez A, Gillan WW, Tan SA. 1992. Elevated plasma glucagon in amyotrophic lateral sclerosis. Neurology 42:1532-1534.

Humans IWGotEoCRt. 2016. Outdoor air pollution. IARC Monogr Eval Carcinog Risks Hum 109:9444.

Kahn SE, Zinman B, Haffner SM, O'Neill MC, Kravitz BG, Yu D, et al. 2006. Obesity is a major determinant of the association of c-reactive protein levels and the metabolic syndrome in type 2 diabetes. Diabetes 55:2357-2364.

Ke YD, van Hummel A, Stevens CH, Gladbach A, Ippati S, Bi M, et al. 2015. Short-term suppression of a315t mutant human tdp-43 expression improves functional deficits in a novel inducible transgenic mouse model of ftld-tdp and als. Acta Neuropathol 130:661-678.

Kim SM, Kim H, Kim JE, Park KS, Sung JJ, Kim SH, et al. 2011. Amyotrophic lateral sclerosis is associated with hypolipidemia at the presymptomatic stage in mice. PLoS One 6:e17985.

Klok MD, Jakobsdottir S, Drent ML. 2007. The role of leptin and ghrelin in the regulation of food intake and body weight in humans: A review. Obes Rev 8:21-34.

Kremens D, Hauser RA, Dorsey ER. 2014. An update on parkinson's disease: Improving patient outcomes. Am J Med 127:S3.

Lippmann M. 1989. Health effects of ozone. A critical review. JAPCA 39:672-695.

Mandillo S, Tucci V, Holter SM, Meziane H, Banchaabouchi MA, Kallnik M, et al. 2008. Reliability, robustness, and reproducibility in mouse behavioral phenotyping: A cross-laboratory study. Physiol Genomics 34:243-255.

Manisalidis I, Stavropoulou E, Stavropoulos A, Bezirtzoglou E. 2020. Environmental and health impacts of air pollution: A review. Front Public Health 8:14. 
Medina DX, Orr ME, Oddo S. 2014. Accumulation of c-terminal fragments of transactive response DNA-binding protein 43 leads to synaptic loss and cognitive deficits in human tdp-43 transgenic mice. Neurobiol Aging 35:79-87.

Miller RG, Mitchell JD, Lyon M, Moore DH. 2002. Riluzole for amyotrophic lateral sclerosis (als)/motor neuron disease (mnd). Cochrane Database Syst Rev:CD001447.

Muddapu VR, Dharshini SAP, Chakravarthy VS, Gromiha MM. 2020. Neurodegenerative diseases is metabolic deficiency the root cause? Front Neurosci 14:213.

Myung W, Lee H, Kim H. 2019. Short-term air pollution exposure and emergency department visits for amyotrophic lateral sclerosis: A time-stratified case-crossover analysis. Environ Int 123:467-475. Nappi F, Barrea L, Di Somma C, Savanelli MC, Muscogiuri G, Orio F, et al. 2016. Endocrine aspects of environmental "obesogen" pollutants. Int J Environ Res Public Health 13.

Ngo ST, Steyn FJ, Huang L, Mantovani S, Pfluger CM, Woodruff TM, et al. 2015. Altered expression of metabolic proteins and adipokines in patients with amyotrophic lateral sclerosis. J Neurol Sci $357: 22-27$.

Orru H. 2019. Ozone and heat-related mortality in europe in 2050 significantly affected by changes in climate, population and greenhouse gas emission. Environmental Research Letters 14.

Ortega Moreno L, Sanz-Garcia A, Fernandez de la Fuente MJ, Arroyo Solera R, Fernandez-Tome S, Marin AC, et al. 2020. Serum adipokines as non-invasive biomarkers in crohn's disease. Sci Rep 10:18027.

Oskarsson B, Horton DK, Mitsumoto H. 2015. Potential environmental factors in amyotrophic lateral sclerosis. Neurol Clin 33:877-888.

Petri S, Korner S, Kiaei M. 2012. Nrf2/are signaling pathway: Key mediator in oxidative stress and potential therapeutic target in als. Neurol Res Int 2012:878030.

Povedano M, Saez M, Martinez-Matos JA, Barcelo MA. 2018. Spatial assessment of the association between long-term exposure to environmental factors and the occurrence of amyotrophic lateral 
sclerosis in catalonia, spain: A population-based nested case-control study. Neuroepidemiology 51:33-49.

Rhee J, Dominici F, Zanobetti A, Schwartz J, Wang Y, Di Q, et al. 2019. Impact of long-term exposures to ambient pm2.5 and ozone on ards risk for older adults in the united states. Chest 156:7179.

Ritz B, Lee PC, Hansen J, Lassen CF, Ketzel M, Sorensen M, et al. 2016. Traffic-related air pollution and parkinson's disease in denmark: A case-control study. Environ Health Perspect 124:351-356.

Rivas-Arancibia S, Guevara-Guzman R, Lopez-Vidal Y, Rodriguez-Martinez E, Zanardo-Gomes M, Angoa-Perez M, et al. 2010. Oxidative stress caused by ozone exposure induces loss of brain repair in the hippocampus of adult rats. Toxicol Sci 113:187-197.

Rothstein JD. 2017. Edaravone: A new drug approved for als. Cell 171:725.

Sacks JD, Fann N, Gumy S, Kim I, Ruggeri G, Mudu P. 2020. Quantifying the public health benefits of reducing air pollution: Critically assessing the features and capabilities of who's airq+ and u.S. Epa's environmental benefits mapping and analysis program - community edition (benmap - ce). Atmosphere (Basel) 11:1-15.

Shore SA. 2019. The metabolic response to ozone. Front Immunol 10:2890.

Sokolowska M, Quesniaux VFJ, Akdis CA, Chung KF, Ryffel B, Togbe D. 2019. Acute respiratory barrier disruption by ozone exposure in mice. Front Immunol 10:2169.

Song J, Zhu J, Tian G, Li H, Li H, An Z, et al. 2020. Short time exposure to ambient ozone and associated cardiovascular effects: A panel study of healthy young adults. Environ Int 137:105579. Stallings NR, Puttaparthi K, Luther CM, Burns DK, Elliott JL. 2010. Progressive motor weakness in transgenic mice expressing human tdp-43. Neurobiol Dis 40:404-414.

Tapia R. 2014. Cellular and molecular mechanisms of motor neuron death in amyotrophic lateral sclerosis: A perspective. Front Cell Neurosci 8:241.

Tefera TW, Steyn FJ, Ngo ST, Borges K. 2021. Cns glucose metabolism in amyotrophic lateral sclerosis: A therapeutic target? Cell Biosci 11:14. 
Thomson EM, Pilon S, Guenette J, Williams A, Holloway AC. 2018. Ozone modifies the metabolic and endocrine response to glucose: Reproduction of effects with the stress hormone corticosterone. Toxicol Appl Pharmacol 342:31-38.

Togashi Y, Shirakawa J, Okuyama T, Yamazaki S, Kyohara M, Miyazawa A, et al. 2016. Evaluation of the appropriateness of using glucometers for measuring the blood glucose levels in mice. Sci Rep $6: 25465$

Vandoorne T, De Bock K, Van Den Bosch L. 2018. Energy metabolism in als: An underappreciated opportunity? Acta Neuropathol 135:489-509.

Vicedo-Cabrera AM, Sera F, Liu C, Armstrong B, Milojevic A, Guo Y, et al. 2020. Short term association between ozone and mortality: Global two stage time series study in 406 locations in 20 countries. BMJ 368:m108.

Wegorzewska I, Bell S, Cairns NJ, Miller TM, Baloh RH. 2009. Tdp-43 mutant transgenic mice develop features of als and frontotemporal lobar degeneration. Proc Natl Acad Sci U S A 106:1880918814.

Yu Y, Su FC, Callaghan BC, Goutman SA, Batterman SA, Feldman EL. 2014. Environmental risk factors and amyotrophic lateral sclerosis (als): A case-control study of als in michigan. PLoS One 9:e101186.

Zarei S, Carr K, Reiley L, Diaz K, Guerra O, Altamirano PF, et al. 2015. A comprehensive review of amyotrophic lateral sclerosis. Surg Neurol Int 6:171.

\section{Tables}


Table 1. Adipokines concentration in the groups of the study and Kruskal-Wallis comparison (n = 16). Values were reported as median (interquartile range); Kruskal-Wallis comparisons were performed. In the case of leptin, Dunn's post hoc test was significant only for Control-O 3 vs. TDP-43FA $(p=0.012)$. Abbreviations: Control; non-transgenic littermates (WT controls), TDP-43; TDP43 ${ }^{\mathrm{A} 315 \mathrm{~T}}$ mice; FA, filtered air, $\mathrm{O}_{3}$; ozone.

\begin{tabular}{|l|l|l|l|l|l|}
\hline Molecule (pg/ml) & Control FA & Control O & TDP-43 FA & TDP-43 O & $p$ \\
\hline Ghrelin & 6.25 & 10.75 & 7.60 & 7.00 & 0.56 \\
\hline Resistin & 11.50 & 11.75 & 3.60 & 8.33 & 0.01 \\
\hline Leptin & 10.75 & 14.25 & 4.40 & 4.66 & 0.0001 \\
\hline
\end{tabular}

Table 2. Metabolic biomarkers of insulin resistance concentration in the groups of the study and Kruskal-Wallis comparison $(\mathbf{n}=\mathbf{1 6})$. Values were reported as median (interquartile range); Kruskal-Wallis comparisons were performed. Abbreviations: Control; non-transgenic littermates (WT controls), TDP-43; TDP43 ${ }^{\mathrm{A} 315 \mathrm{~T}}$ mice; FA, filtered air, $\mathrm{O}_{3}$; ozone.

\begin{tabular}{|l|l|l|l|l|l|}
\hline Molecule (pg/ml) & Control FA & Control O & TDP-43 FA & TDP-43 O & $p$ \\
\hline GIP & 5.62 & 7.87 & 8.00 & 14.00 & 0.12 \\
\hline GLP-1 & 6.37 & 6.12 & 10.20 & 11.67 & 0.30 \\
\hline Glucagon & 5.25 & 7.62 & 11.40 & 9.16 & 0.28 \\
\hline Insulin & 5.62 & 8.00 & 9.50 & 11.33 & 0.45 \\
\hline PAI-1 & 5.00 & 7.50 & 10.40 & 11.33 & 0.25 \\
\hline
\end{tabular}

\section{Figure Legends}

Fig. 1. $\mathrm{O}_{3}$ exposure beginning at the asymptomatic state of disease does not alter body mass in TDP-43 ${ }^{\text {A315T }}$ mice. Body weight was monitored daily in WT controls and TDP-43 ${ }^{\mathrm{A} 315 \mathrm{~T}}$ mice exposed to $\mathrm{FA}$ or $\mathrm{O}_{3}$ for 15 days, beginning at the asymptomatic state, at 42 days of age ( $\sim 6$ weeks of age). No differences in weight gain between groups was determined. Values are expressed as a mean \pm SEM. Comparison between groups was performed by two-way ANOVA followed by Tukey test, 
unless stated otherwise. Abbreviations: Control; non-transgenic littermates (WT controls), TDP-43; TDP43 ${ }^{\text {A315T }}$ mice; FA, filtered air, $\mathrm{O}_{3}$; ozone. Corresponding graph as control-FA $(n=6$, black square and solid line $)$, control- $\mathrm{O}_{3}(\mathrm{n}=6$, blue square and dashed line $)$, TDP-43 ${ }^{\mathrm{A} 315 \mathrm{~T}}-\mathrm{FA}(\mathrm{n}=3$, green circles and solid line), TDP-43 ${ }^{\mathrm{A} 315 \mathrm{~T}}-\mathrm{O}_{3}(\mathrm{n}=3$, orange circles and dashed line $)$.

Fig. 2. $\mathrm{O}_{3}$ exposure beginning at the asymptomatic state of disease does not alter body mass change but significantly improves motor performance in TDP-43 ${ }^{\mathrm{A315T}}$ mice. (A) Body weight was monitored over time in WT controls and TDP-43 ${ }^{\mathrm{A} 315 \mathrm{~T}}$ mice exposed to FA or $\mathrm{O}_{3}$. Starting weight on week 8. No significant differences were observed between FA-exposed or $\mathrm{O}_{3}$-exposed TDP$43^{\mathrm{A} 315 \mathrm{~T}}$ mice. (B) Average disease onset and disease duration (C) was determined in WT controls and TDP-43 $3^{\mathrm{A} 315 \mathrm{~T}}$ mice exposed to $\mathrm{FA}$ or $\mathrm{O}_{3}$ using body weight as a physiological parameter. Comparatively the disease duration was higher in TDP-43 $3^{\mathrm{A} 315 \mathrm{~T}}$ mice in responses to $\mathrm{O}_{3}$. (D) Behavioral assessment of motor function was performed in WT controls and TDP-43 ${ }^{\mathrm{A} 315 \mathrm{~T}}$ mice exposed to FA or $\mathrm{O}_{3}$ over time. Significant differences between FA- and $\mathrm{O}_{3}$-exposed mice were seen. Values are expressed as a mean \pm SEM. Comparison between groups was performed by two-way ANOVA, where ${ }^{*} p<0.05$ vs. FA-exposed WT control mice; ${ }^{* *} p<0.05$ vs. $\mathrm{O}_{3}$-exposed WT control mice; \& $p<0.05$ vs. $\mathrm{O}_{3}$-exposed TDP-43 ${ }^{\mathrm{A} 315 \mathrm{~T}}$ mice. Abbreviations: Control; non-transgenic littermates (WT controls), TDP-43; TDP43 ${ }^{\mathrm{A} 315 \mathrm{~T}}$ mice; FA, filtered air, $\mathrm{O}_{3}$; ozone. Corresponding graphs as per A., i.e. control-FA $\left(n=6\right.$, black square and solid line), control- $\mathrm{O}_{3}(n=6$, blue square and dashed line), TDP-43 ${ }^{\mathrm{A} 315 \mathrm{~T}}-\mathrm{FA}(\mathrm{n}=3$, green circles and solid line $), \mathrm{TDP}-43^{\mathrm{A} 315 \mathrm{~T}}-\mathrm{O}_{3}(\mathrm{n}=3$, orange circles and dashed line).

\section{Fig. 3. $\mathrm{O}_{3}$ exposure beginning at the asymptomatic state increased plasma glucose levels in TDP-} $\mathbf{4 3}^{\mathrm{A315T}}$ mice. Plasma glucose concentration was measured in WT controls and TDP-43 ${ }^{\mathrm{A} 315 \mathrm{~T}}$ mice exposed to $\mathrm{FA}$ or $\mathrm{O}_{3}$ at disease end-stage ( $95-100 \pm 2$ days). Quantification revealed the highest levels in response to $\mathrm{O}_{3}$ exposure in TDP-43 ${ }^{\mathrm{A} 315 \mathrm{~T}}$ mice. In addition, significant differences between FA- and $\mathrm{O}_{3}$-exposed WT mice were seen. Values are expressed as a mean \pm SEM. Comparison between groups was performed by two-way ANOVA, where $* p<0.05$ vs. FA-exposed WT control 
mice; $* * p<0.05$ vs. $\mathrm{O}_{3}$-exposed WT control mice. Abbreviations: Control; non-transgenic littermates (WT controls), TDP-43; TDP43 ${ }^{\mathrm{A} 315 \mathrm{~T}}$ mice; FA, filtered air, $\mathrm{O}_{3}$; ozone.

Fig. 4. Spearman correlations for the adipocytokines ghrelin, resistin and leptin in WT controls and TDP-43 ${ }^{\mathrm{A315T}}$ mice exposed to $\mathrm{FA}$ or $\mathrm{O}_{3}$. In this figure, the red and blue squares refer to negative and positive correlations, respectively; ${ }^{*} p<0.05$. The color intensity of the squares is proportional to the correlation coefficient. In the legend at the right size, the intensity of the color shows the rate of correlations and the corresponding relationships.

Fig. 5. Spearman correlations for metabolic proteins in WT controls and TDP-43 ${ }^{\mathrm{A315T}}$ mice exposed to $\mathbf{F A}$ or $\mathbf{O}_{3}$. In this figure, the red and blue squares refer to negative and positive correlations, respectively; ${ }^{*} p<0.05$. The color intensity of the squares is proportional to the correlation coefficient. In the legend at the right size, the intensity of the color shows the rate of correlations and the corresponding relationships. 


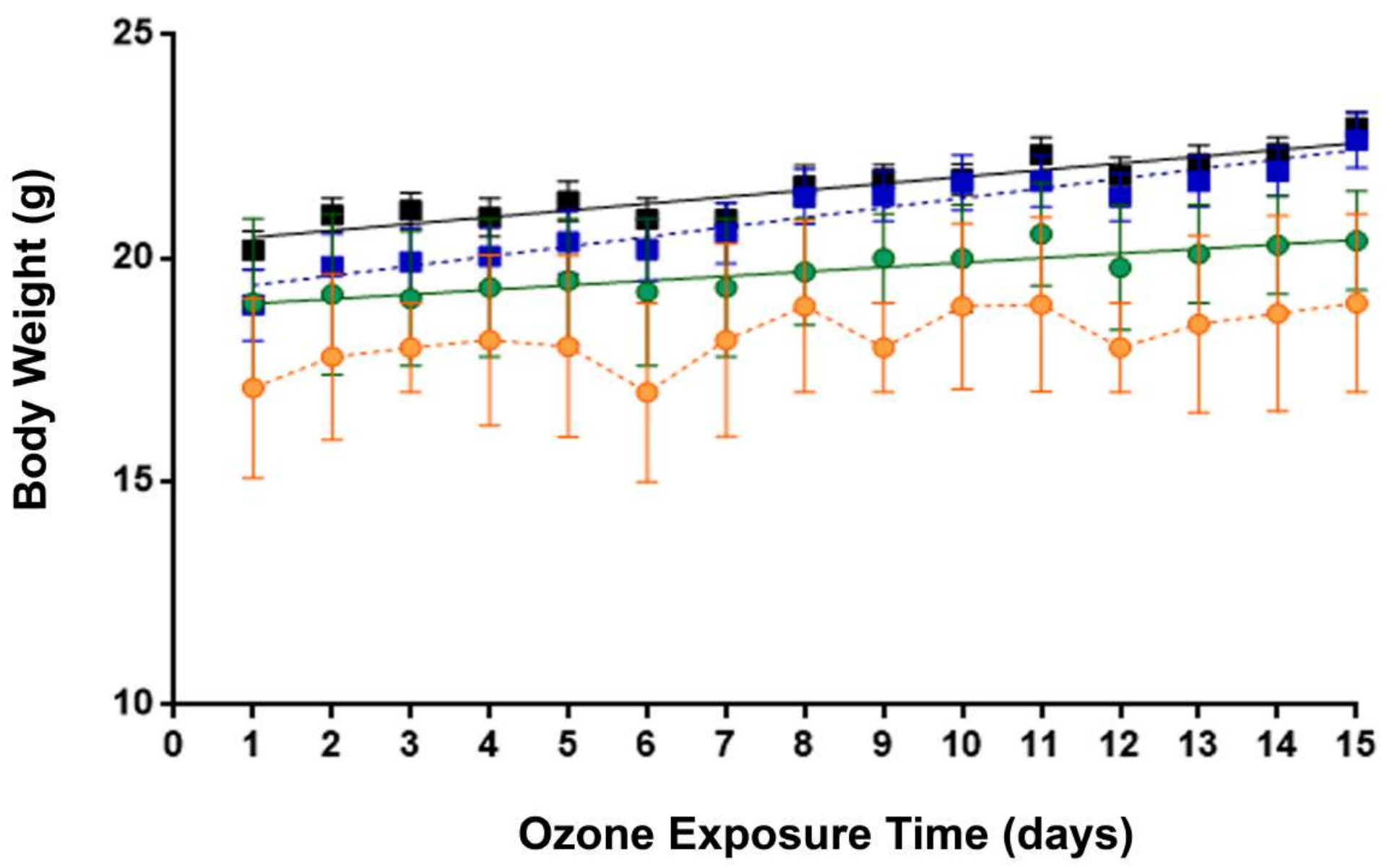


A
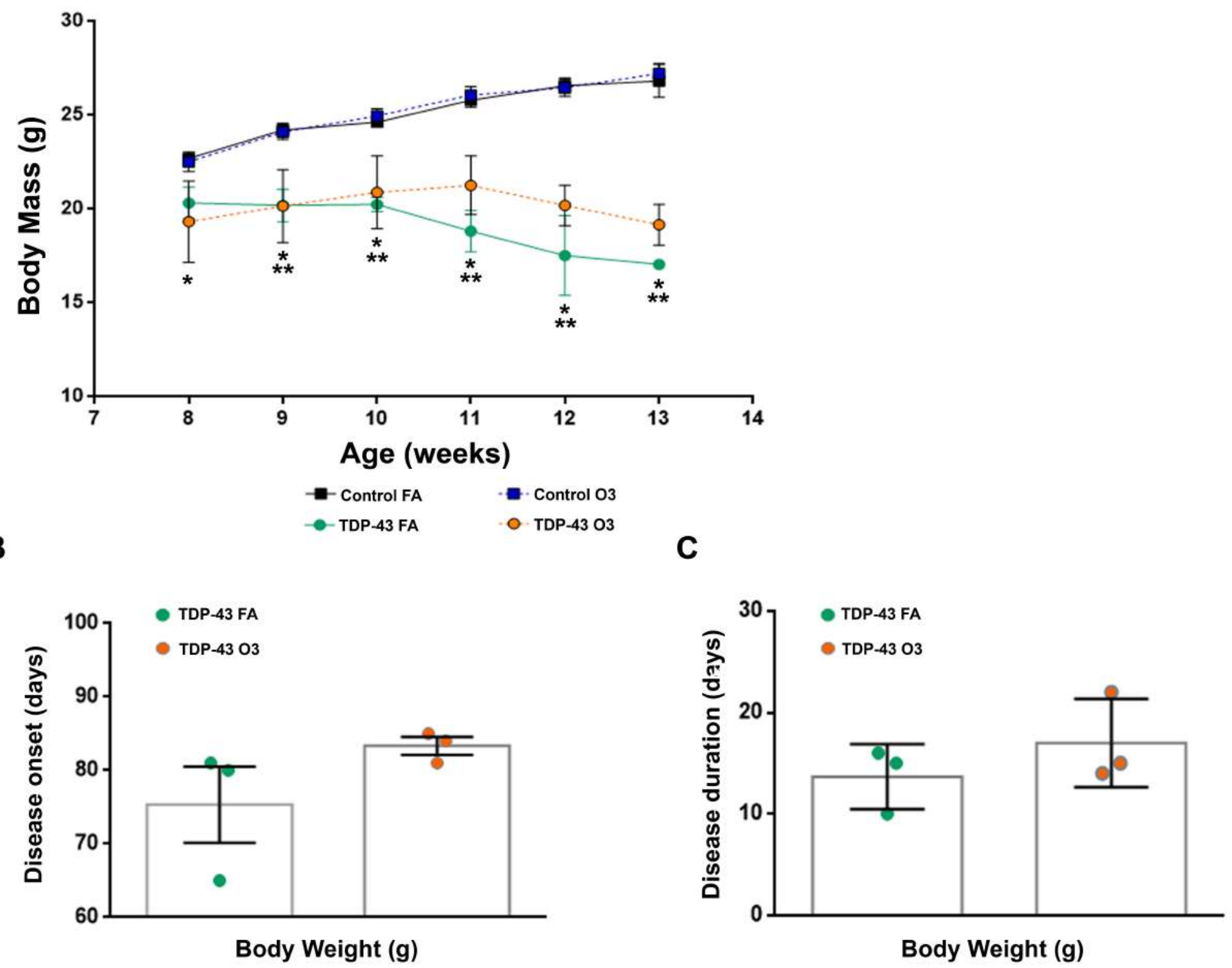

D

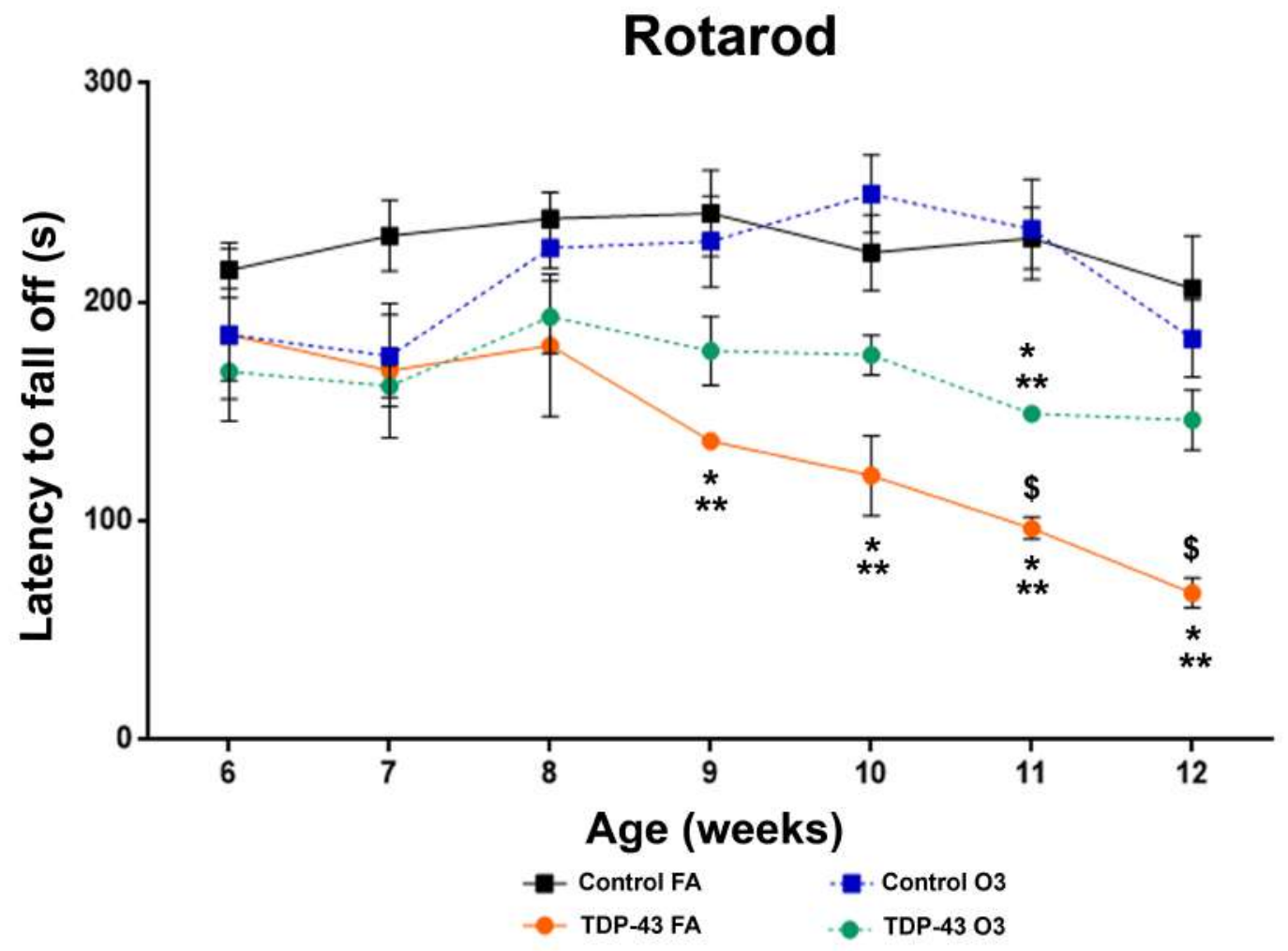




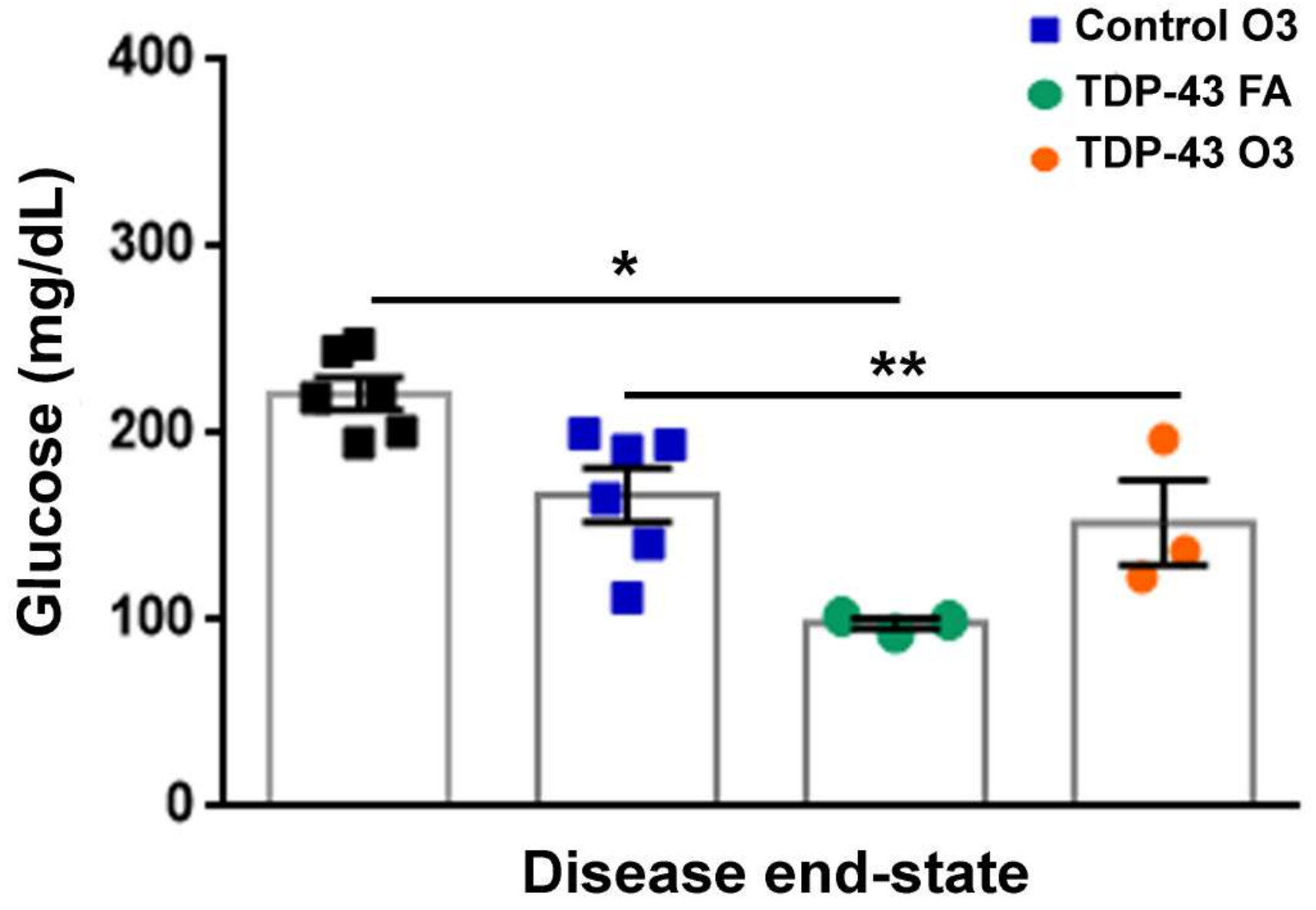


A

\section{Spearman correlation for WT}

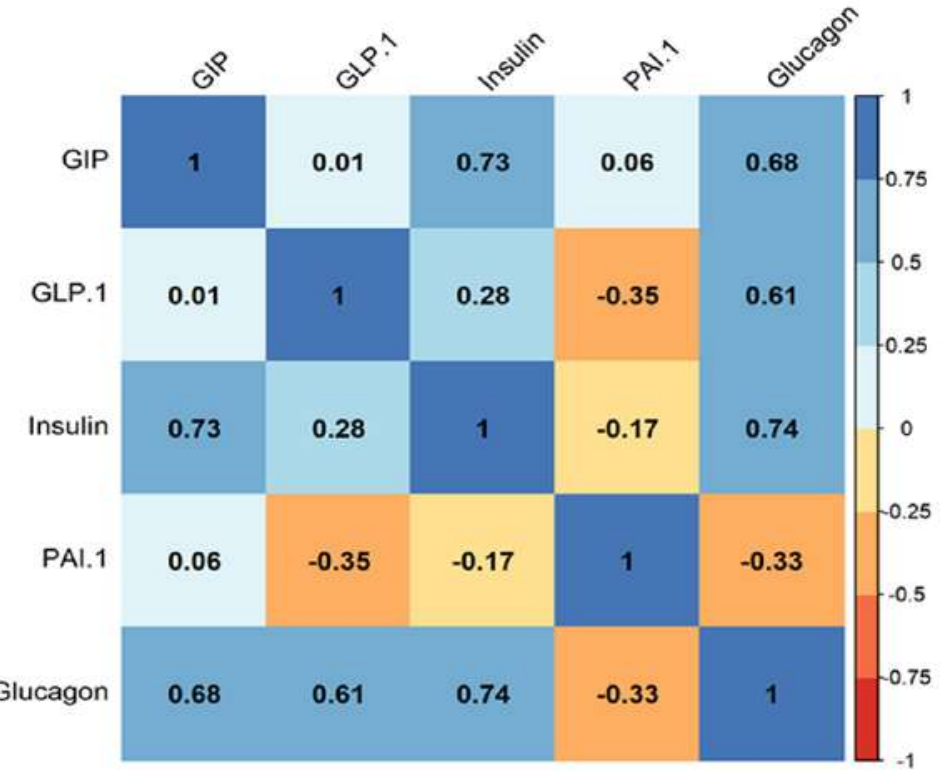

B

\section{Spearman correlation for TDP-43}

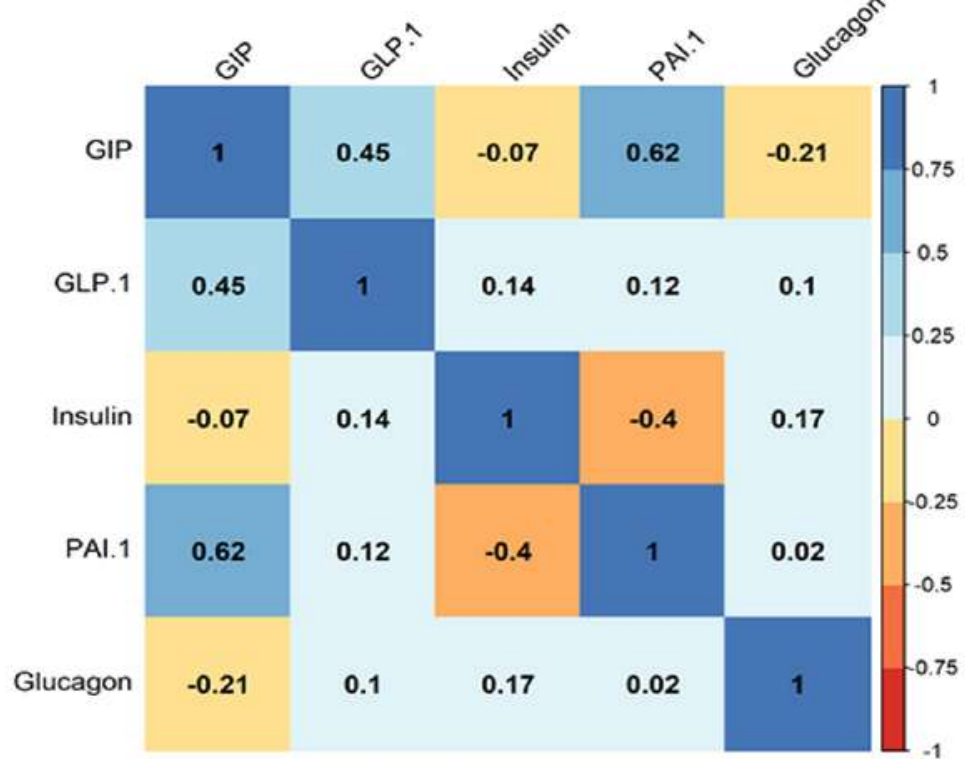

